\title{
Exploring The Multiple Intelligences Of Community College Students Enrolled In Online Courses
}

\author{
Daniel Gutierrez, (E-mail: dgutierrez@valenciacc.edu), Valencia Community College \\ Kathleen Perri, Valencia Community College \\ Alvin Quackenbush, Valencia Community College
}

\begin{abstract}
While a plethora of research exists concerning Gardner's theory of Multiple Intelligences (MI), virtually all of the research is focused on grades $K-12$. Few research studies on MI have been conducted with college students. The present study explores and profiles the Multiple Intelligences of community college students $(N=90)$ enrolled in online courses during the summer of 2006. The study is the first in a series of ongoing research that will explore MI theory among community college students. An overall profile of the students' Multiple Intelligences are presented as well as descriptive comparisons between male and female profiles, selected majors and course type comparisons. Implications and recommendations for further MI research are also discussed.
\end{abstract}

\section{INTRODUCTION}

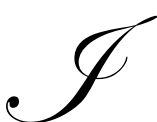

t has been more than twenty years since Gardner's (1983) theory of multiple intelligences was first introduced. Since then, a plethora of literature on multiple intelligences has followed, generating wide support for the theory (see Barrington, 2004; Gardner, 1999; Kornhaber, 2002 and Shearer, 2004 just to mention a few). Very few theories in the history of educational research have had the impact of MI (Shearer, 2004) and according to Kornhaber (2002), Gardner's MI (1983) theory has been adopted and implemented for use in schools throughout the world with diverse student populations including special needs, gifted, and juvenile delinquents.

While almost a quarter of a century has passed since Gardner first introduced his theory of Multiple Intelligences (1983), apart from debates of whether or not MI theory can be applied to students in higher education (Barrington, 2004), this area has received little attention and an exiguous amount of research concerning MI theory and tertiary education exists. Stage, Muller, Kinzie, \& Simmons (1998), for example, note the scant amount of research concerning multiple intelligences and higher education. In a review of the literature they state that little research on MI exists which addresses college students. Additionally, our review of the literature discovered only two studies that discussed MI and college level students or actually applied any type of statistical analysis of Gardner's Theory, as it relates to higher education (see Kezar, 2001; Johnson \& White, 2002).

The fact that educators have so readily taken to MI is quite remarkable, (Kornhaber, 2002) given the absence of information and structure to support the theory's implementation, and as Kornhaber (2002) argues, it is reasonable to ask why educators have so readily adopted Multiple Intelligences theory. Given this void in the literature, our goal here is to develop a series of research studies which address the lack of research in this area as it applies to college students. The present study is the first in a series of studies to follow. In this paper, we provide a profile of multiple intelligences of college students enrolled in online courses and compare them across several dimensions.

\section{REVIEW OF MULTIPLE INTELLIGENCES THEORY}

Multiple Intelligences (MI) theory was first articulated by Gardner (1983) in Frames of Mind: The Theory of Multiple Intelligences. MI theory, as it has come to be known, postulates that a unitary concept of intelligence (g) 
lacks the capacity to accurately assess the strength and weaknesses of individuals. This argument provides a framework for MI theory's two major claims. First, all individuals possess some level of all the intelligences articulated in the theory, and second, just as we all possess different physical features, personality types and levels of temperament, we also exhibit different profiles of multiple intelligences (Gardner, 1983).

Originally, Gardner first proposed seven different intelligences and later added an eighth in 1995, known as naturalist intelligence (Gardner, 2004). Today, he continues to contemplate whether other areas of intelligence exist and has written in support of a ninth, existential intelligence however, he is yet to include existential intelligence, which consists of the individual's ability to ponder fundamental questions about life, death, and existence (Gardner, 2004). Gardner's theory claims that all humans possess multiple intelligences and just like variations that exist in our physical appearance, each of our intelligent profiles varies as well (Gardner, 2004).

The eight areas of intelligences include: 1) linguistic, 2) logical-mathematical, 3) musical, 4) spatial, 5) bodily-kinesthetic, 6) interpersonal, 7) intrapersonal, and 8) naturalist (Gardner 1983). One of Gardner's (1983) criticisms of how we have historically viewed intelligence is that most standard measures of intelligence primarily probe linguistic and logical intelligence; while others examine spatial intelligence. The remaining intelligences have almost entirely been ignored. Below is a brief explanation of each of the eight Multiple Intelligences that we profile in the present study. Because Gardner himself (2004) indicates that he has not yet added existential intelligence, we have excluded existential intelligence from the present study.

- Linguistic intelligence involves spoken and written language. It is the ability to learn languages, and the capacity to use language to accomplish certain goals. This intelligence includes the capacity to effectively use language to express oneself. Gardner attributes high levels of linguistic intelligence to writers, poets, lawyers and speakers.

- Logical-mathematical intelligence involves the capacity to analyze problems logically, carry out mathematical functions, and investigate problems scientifically. It includes the ability to detect patterns, reason deductively and think logically. This intelligence is most often associated with scientific and mathematical thinking. High levels of logical intelligence are related to accountants, statisticians, and computer programmers.

- Musical intelligence involves the performance, composition, and appreciation of musical patterns as well as the capacity to recognize and compose musical pitches, tones, and rhythms. Gardner also claims that musical intelligence is structurally parallel to linguistic intelligence.

- Bodily-kinesthetic intelligence involves the potential of using one's whole body or parts of the body to solve problems by using mental abilities to coordinate bodily movements. This includes athletes and dancers as well as mechanics, surgeons and craftspersons.

- Spatial intelligence is the potential to recognize and use the patterns of wide space and more confined areas and is associated with ones' visual capacity. Illustrators, interior decorators, architect, graphics designer, and photographers can be found in this category.

- Interpersonal intelligence is concerned with the capacity to understand the intentions, motivations and desires of other people. It allows people to work effectively with others. Educators, salespeople, religious and political leaders and counselors all need a well-developed interpersonal intelligence.

- Intrapersonal intelligence entails the capacity to understand oneself, to appreciate one's feelings, fears and motivations. In Gardner's view it involves having an effective working model of ourselves, and to be able to use such information to regulate our lives. Counselors, planners, social workers, psychologists, writers and religious leaders are related to intrapersonal intelligence.

- Naturalist intelligence deals with classification abilities or the flora and fauna of one's environment. Biologist would be classified as naturalist as would those individuals who have the ability to recognize and identify species and subspecies.

\section{METHODOLOGY}

Using McKenzie's (2005) assessment instrument of Multiple Intelligences, we surveyed students enrolled in criminal justice and speech courses $(\mathrm{N}=90)$ during the summer semester of 2006. Based on the lack of literature and 
the non-solidification of existentialism as being one of the multiple intelligences, we excluded any data for existentialism. Additional consideration was also given to the fact that existentialism is difficult to translate into curricular activities.

Next, we distributed the survey to our students via electronic mail so that our online students could complete the survey. In addition to the McKenzie instrument, we also developed a short survey that allowed us to collect basic demographic data such as age, race/ethnicity and GPA from the students enrolled in the courses. We then asked students to complete the survey and results were transferred into an SPSS file for analysis. Only students enrolled in online courses during the summer of 2006 were profiled.

Finally, we collapsed each of the intelligence scores and created three levels of intelligence which included low, moderate and high levels of intelligence scores. Students that scored from 0 to 4 in any intelligence were considered low, scores ranging from 5 to 7 were considered moderate, and scores that fell between 8 and 10 were considered high. This produced a low, moderate or high range profile for each of the eight intelligences we assessed.

\section{FINDINGS}

A total of 105 students were initially enrolled in both the communication and criminal justice courses we surveyed. Of the original 105 enrolled, 15 were excluded from the analysis because they failed to complete any of the requested information. They were completely inactive and withdrew or were withdrawn from the courses. The basic demographic data collected for the remaining 90 students revealed the average age of the students was 24 year of age with a standard deviation of 5.4 years, ranging from 17 years of age for the youngest to 41 years of age for the oldest. Regarding gender, 71 percent of the sample consisted of female students, while the remaining 29 percent were males. The racial/ethnicity breakdown of the group consisted of 72.6 percent Caucasian,10.7 percent Black, 10.7 percent Hispanic/Latino and 6 percent other. Student GPA scores ranged from 1.8 to 4.0, with a mean GPA of 2.9 with a standard deviation of .56. When we examined their choice of majors, with exception of the social sciences, all of the categories consisted of only one or two students. We therefore combined them together with all other majors. 28.4 were social science majors while the remaining 71.6 made up the group of all other majors.

Table 1: Overall Multiple Intelligences Profiles

\begin{tabular}{|l|c|c|c|}
\hline Multiple Intelligences (N 90) & Low & Moderate & High \\
\hline 1) Naturalist & $31.1 \%$ & $43.3 \%$ & $25.6 \%$ \\
\hline 2) Musical & $7.8 \%$ & $54.4 \%$ & $37.8 \%$ \\
\hline 3) Logical & $13.3 \%$ & $46.7 \%$ & $40.0 \%$ \\
\hline 4) Interpersonal & $26.7 \%$ & $46.7 \%$ & $26.7 \%$ \\
\hline 5) Kinesthetic & $15.6 \%$ & $35.6 \%$ & $48.9 \%$ \\
\hline 6) Verbal/Linguistic & $40.0 \%$ & $38.9 \%$ & $21.1 \%$ \\
\hline 7) Intrapersonal & $4.4 \%$ & $14.4 \%$ & $81.1 \%$ \\
\hline 8) Visual/Spatial & $22.2 \%$ & $43.3 \%$ & $34.4 \%$ \\
\hline
\end{tabular}

The Multiple Intelligences assessments produced an overall profile of the percent of students that were classified as either having low, moderate or high levels of intelligences for each of the intelligences. Overall, the majority of students, 43.3 percent, scored in the moderate range for naturalist intelligence while 31.1 percent were in the low range and 25.6 percent in the high range. For musical intelligence, the majority, 54.4 percent, scored in the moderate range while 7.8 percent were in the low range and 37.8 percent in the range. In terms of logical intelligence, 46.7 percent were assessed with moderate levels, 13.3 percent low and 40 percent with high levels of logical intelligence. With regards to interpersonal intelligence, 46.7 percent scored in the moderate range, while 26.7 percent fell both into the low and high range. Kinesthetically, the largest proportion of students was in the high range, 48.9 percent, while 15.6 percent were low range and 35.6 percent high range. The greatest proportion of scores (40\%) in the verbal/linguistic area of intelligence was in the low range, while 38.9 percent fell into the moderate range and only 21.1 percent in the high range. The greatest proportion of high level scores was in the intrapersonal intelligence category. 81.1 percent of the students had high levels of intrapersonal intelligence while 4.4 percent scored in the low 
range and 14.4 percent in the moderate range. For visual/spatial intelligence, 43.3 percent were in the moderate range while 22.2 percent were low and 34.4 high.

When we examined Multiple Intelligences by gender, substantial differences were found between male and female students in all Multiple Intelligences. Males had a higher proportion of students in the high level range for five of the eight intelligences. This included the following: naturalist (36\% v 22\%), logical (44\% v 39.7\%), kinesthetic (60\% v 46\%), intrapersonal (92\% v 79.4\%), and visual/spatial (44\% v 31.7\%) intelligences. Females had a higher proportion of students in the high level range for musical (41.3\% v. 32\%), interpersonal $(30.2 \% \mathrm{v} 20 \%)$, and verbal/linguistic $(25.4 \%$ v $12 \%)$. The low and moderate range proportions are indicted in table 2.

Table 2: Multiple Intelligences Profiles By Gender

\begin{tabular}{|l|c|c|c|c|c|c|}
\hline \multirow{2}{*}{$\begin{array}{c}\text { Multiple } \\
\text { Intelligences }\end{array}$} & \multicolumn{3}{c|}{$\begin{array}{c}\text { Male Students } \\
\text { (N = 25) }\end{array}$} & \multicolumn{3}{c|}{$\begin{array}{c}\text { Females Students } \\
(\mathbf{N}=\mathbf{6 3})\end{array}$} \\
\cline { 2 - 7 } & Low & Moderate & High & Low & Moderate & High \\
\hline 1) Naturalist & $36 \%$ & $28 \%$ & $36 \%$ & $27 \%$ & $50.8 \%$ & $22.2 \%$ \\
\hline 2) Musical & $8 \%$ & $60 \%$ & $32 \%$ & $4.8 \%$ & $54 \%$ & $41.3 \%$ \\
\hline 3) Logical & $4 \%$ & $52 \%$ & $44 \%$ & $14.3 \%$ & $46 \%$ & $39.7 \%$ \\
\hline 4) Interpersonal & $28 \%$ & $52 \%$ & $20 \%$ & $23.8 \%$ & $46 \%$ & $30.2 \%$ \\
\hline 5) Kinesthetic & $16 \%$ & $24 \%$ & $60 \%$ & $12.7 \%$ & $41.3 \%$ & $46 \%$ \\
\hline 6) Verbal/Linguistic & $44 \%$ & $44 \%$ & $12 \%$ & $36.5 \%$ & $38.1 \%$ & $25.4 \%$ \\
\hline 7) Intrapersonal & $0 \%$ & $8 \%$ & $92 \%$ & $3.2 \%$ & $17.5 \%$ & $79.4 \%$ \\
\hline 8) Visual/Spatial & $24 \%$ & $32 \%$ & $44 \%$ & $19 \%$ & $49.2 \%$ & $31.7 \%$ \\
\hline
\end{tabular}

When separated out by major, substantial differences existed between social science majors and all other majors in five of the eight areas. Social science majors had higher proportions of students in the high level range for interpersonal ( $31.6 \%$ v $23.1 \%)$, kinesthetic $(52.6 \%$ v $46.2 \%)$, verbal/linguistic $(26.3 \%$ v $17.3 \%)$, intrapersonal $(92.1 \%$ v $73.1 \%)$, and visual/spatial ( $42.1 \%$ v $28.8 \%)$ intelligences. The naturalist, musical and logical multiple intelligences had only slight differences in these areas (see table 3 ).

Table 3: Multiple Intelligences Profiles By Major

\begin{tabular}{|l|c|c|c|c|c|c|}
\hline \multicolumn{1}{c|}{$\begin{array}{c}\text { Multiple } \\
\text { Intelligences }\end{array}$} & \multicolumn{3}{c|}{$\begin{array}{c}\text { Social Science Majors } \\
\text { (N = 25) }\end{array}$} & \multicolumn{3}{c|}{$\begin{array}{c}\text { All Other Majors } \\
(\mathbf{N}=63)\end{array}$} \\
\hline & Low & Moderate & High & Low & Moderate & High \\
\hline 1) Naturalist & $34.2 \%$ & $39.5 \%$ & $26.3 \%$ & $28 \%$ & $46.2 \%$ & $25 \%$ \\
\hline 2) Musical & $7.9 \%$ & $52.6 \%$ & $39.5 \%$ & $7.7 \%$ & $55.8 \%$ & $36.5 \%$ \\
\hline 3) Logical & $15.8 \%$ & $44.7 \%$ & $39.5 \%$ & $11.5 \%$ & $48.1 \%$ & $40.4 \%$ \\
\hline 4) Interpersonal & $18.4 \%$ & $50 \%$ & $31.6 \%$ & $32.7 \%$ & $44.2 \%$ & $23.1 \%$ \\
\hline 5) Kinesthetic & $13.2 \%$ & $34.2 \%$ & $52.6 \%$ & $17.3 \%$ & $36.5 \%$ & $46.2 \%$ \\
\hline 6) Verbal/Linguistic & $34.2 \%$ & $39.5 \%$ & $26.3 \%$ & $44.2 \%$ & $38.5 \%$ & $17.3 \%$ \\
\hline 7) Intrapersonal & $2.6 \%$ & $5.3 \%$ & $92.1 \%$ & $5.8 \%$ & $21.2 \%$ & $73.1 \%$ \\
\hline 8) Visual/Spatial & $26.3 \%$ & $31.6 \%$ & $42.1 \%$ & $19.2 \%$ & $51.9 \%$ & $28.8 \%$ \\
\hline
\end{tabular}

Comparing the criminal justice students to those enrolled in the communications courses, we found substantial differences in the proportion of criminal justice students in the high level range in four of the eight Multiple Intelligences. These included naturalist (28.3\% v 21.6\%), logical (43.4\% v 35.1\%), kinesthetic (56.6\% v $37.8 \%)$ and intrapersonal $(92.5 \%$ v $64.9 \%)$. While the naturalist, musical and interpersonal intelligences varied only slightly, the verbal/linguistic intelligence has a disproportionate amount of students in that fell into the low level range. Of the communication students, 51.4 percent scored in the low level of verbal/linguistic intelligence while 32.1 percent of the criminal justice students scored in the low range. 
Table 4: Multiple Intelligences Profiles By Course Type

\begin{tabular}{|c|c|c|c|c|c|c|}
\hline \multirow[t]{2}{*}{$\begin{array}{c}\text { Multiple } \\
\text { Intelligences }\end{array}$} & \multicolumn{3}{|c|}{$\begin{array}{c}\text { Criminal Justice Courses } \\
(\mathbf{N}=\mathbf{5 3})\end{array}$} & \multicolumn{3}{|c|}{$\begin{array}{c}\text { Communication Courses } \\
(\mathbf{N}=37)\end{array}$} \\
\hline & Low & Moderate & High & Low & Moderate & High \\
\hline 1) Naturalist & $30.2 \%$ & $41.5 \%$ & $28.3 \%$ & $32.4 \%$ & $45.9 \%$ & $21.6 \%$ \\
\hline 2) Musical & $7.5 \%$ & $52.8 \%$ & $39.6 \%$ & $8.1 \%$ & $56.8 \%$ & $35.1 \%$ \\
\hline 3) Logical & $17 \%$ & $39.6 \%$ & $43.4 \%$ & $8.1 \%$ & $56.8 \%$ & $35.1 \%$ \\
\hline 4) Interpersonal & $24.5 \%$ & $47.2 \%$ & $28.3 \%$ & $29.7 \%$ & $45.9 \%$ & $24.3 \%$ \\
\hline 5) Kinesthetic & $9.4 \%$ & $34 \%$ & $56.6 \%$ & $24.3 \%$ & $37.8 \%$ & $37.8 \%$ \\
\hline 6) Verbal/Linguistic & $32.1 \%$ & $43.4 \%$ & $24.5 \%$ & $51.4 \%$ & $32.4 \%$ & $16.2 \%$ \\
\hline 7) Intrapersonal & $3.8 \%$ & $3.8 \%$ & $92.5 \%$ & $5.4 \%$ & $29.7 \%$ & $64.9 \%$ \\
\hline 8) Visual/Spatial & $24.5 \%$ & $39.6 \%$ & $35.8 \%$ & $18.9 \%$ & $48.6 \%$ & $32.4 \%$ \\
\hline
\end{tabular}

\section{DISCUSSION/LIMITATIONS}

Using an instrument developed by McKenzie (2005), we examined Multiple Intelligences of 90 students enrolled in criminal justice and communications classes delivered online. Scores obtained from the instrument for each Multiple Intelligence were then grouped into three ranges, low (0-4), moderate (5-7) and high (8-10). Next, we developed an MI profile of the entire sample (see table 1). We then developed an MI profile and compared students across three dimensions; by gender (see table 2), major (see table 3) and course type (see table 4).

The profiles consistently demonstrate two areas of multiple intelligence that produced substantial differences, intrapersonal and verbal/linguistic intelligence. Intrapersonal levels were consistently high across all dimensions. Overall, 81.1 percent of the students recorded high levels of intrapersonal intelligence. For males, it was 92 percent, social science majors, 92.1 percent, and by course type for students enrolled in criminal justice courses, 92.5 percent. For verbal/linguistic intelligence, a substantial proportion of students recorded low range scores, which include the following. Overall, 40 percent of the students had low range verbal/linguistic intelligence scores. This proportion increased when we examined the profiles across gender, majors and course type. For gender, 44 percent of the males recorded low range scores compared to 36.5 percent of the females. By majors, 34.2 percent of the social science majors recorded low verbal/linguistic intelligence scores however; 44.2 percent of all other majors had low range scores. The highest proportion of students that recorded low range scores in the verbal/linguistic area were the students enrolled in the communications classes. 51.4 percent of these students had low range verbal/linguistic scores.

While the findings indicate substantial differences in student profiles of Multiple Intelligences, we caution against generalizing the data across populations. First, our sample is a sample of convenience and only includes 90 students enrolled in summer online courses. Next, the study only provides a descriptive analysis of the profiles for the students sampled. Finally, since few studies have been conducted with college students and Multiple Intelligences theory, comparisons with other findings was problematic. One study however, conducted by Johnson and White (2002), also found a high proportion high intrapersonal intelligence scores among criminal justice students and a high proportion of low levels of verbal/linguistic scores.

Considering these limitations however; the findings raise some interesting questions for further research. First, can these scores be used to predict student success? Second, can pedagogical or curriculum applications be altered to improve success rates if we can, in fact, use these scores to predict student success? Third, are there differences in Multiple Intelligences between traditional students and students who prefer to take courses online? Finally, how else can educators use multiple intelligence assessments or profiles to improve education and delivery methods in higher education? Hopefully, these and other important questions will be addressed as we continue to research multiple intelligences within the context of higher education.

Finally, Kezar (2001) believes that MI has several implications for higher education but questions why MI theory is not more frequently included as part of the dialogue at institutions of higher learning or at national conferences. Among the implications Kezar (2002) has noted; access, diversity, accountability and assessment present the greatest implications for higher education. These could have profound impact on the admissions process, delivery 
methods that address diverse intelligences and learning needs, and finally, MI could be interwoven into assessing learning outcomes. Given this broad range of implications, additional research on MI and higher education populations should be forthcoming.

\section{REFERENCES}

1. Barrington, E. (2004). Teaching to student diversity in higher education: How multiple intelligence theory can help. Teaching in Higher Education, Vol. 9, No. 4, 421-434.

2. Gardner, H. (1983). Frames of mind: The theory of multiple intelligences. New York: Basic Books.

3. Gardner, H. (1998). Are there additional intelligences? The case for naturalist, spiritual, and existential intelligences. In J. Kane (Ed.), Education, information, and transformation (pp. 111-131). Upper Saddle River, NJ: Merrill-Prentice Hall.

4. Gardner, H. (1999). Intelligence reframed: Multiple intelligences for the 21 st century. New York: Basic Books.

5. Gardner, H. (2004). A multiplicity of intelligences: In tribute to Professor Luigi Vignolo. Available at: http://www.howardgardner.com/Papers/documents/T-101\%20A\%20Multiplicity \%20REVISED.pdf

6. Johnson, K. \& White, J. T. (2002). The use of multiple intelligences in criminal justice education. Journal of Criminal Justice Education, 13, 2, 369-386.

7. Kezar, A. (2001). Theory of multiple intelligences: Implications for higher education. Innovative Higher Education, 26, 2, 141-154.

8. Kornhaber, M. L. (2002). Multiple intelligences: From the ivory tower to the dusty classroom - But why? Teachers College Record Volume 106, Number 1, January 2004, pp. 67-76.

9. McKenzie, W. (2005). Multiple Intelligences and instructional technology. Eugene, OR: ISTE Publications.

10. Shearer, B. (2004). Multiple intelligences theory after 20 years. Teachers College Record, Vo. 106, No. 1, 216.

11. Stage, F., Muller, P., Kinzie, J., \& Simmons, A. (1998). Creating learning-centered classrooms: What does learning theory have to say? Washington, DC. Higher Education Report Series, $26,4$. 